\title{
Research of the adsorption of aliphatic carboxylic acids on the surface of polysorb
}

\author{
(C) Alexander A. Kimyashov, ${ }^{+}$Alexander V. Syromolotov, and Maksim O. Pavlov \\ Department of Chemical Technology and Computational Chemistry. Chelyabinsk State University. \\ Molodogvardeytsev St., 70b. Chelyabinsk, 454021. Chelyabinsk Region. Russia. \\ Phone:+7 (351) 799-70-64.E-mail: kimyashov@mail.ru
}

Keywords: polysorb, adsorption, aliphatic carboxylic acids.

*Supervising author; ${ }^{+}$Corresponding author

\begin{abstract}
The enterosorbent "Polysorb" is a highly dispersed powder of silicon dioxide. In medicine, it is used as a detoxifier for poisoning with organic substances and heavy metals. Recently, the direction in pharmaceuticals related to targeted delivery of medicines has begun to develop. One of the carriers of medicinal substances is highly dispersed silicon dioxide. There are explorations that show that with simultaneous oral administration of highly dispersed silicon dioxide and the antibiotic amphotericin, the concentration of the latter in the blood increases significantly. Recently, there have been studies showing that delivering propionic acid to the gut reduces fat accumulation in overweight people.

The goal of this work is study the adsorption of aliphatic carboxylic acids, namely: formic, acetic, propionic on the surface of polysorb.

Using electron microscopy, it was shown that polysorb powder consists of particles of different sizes and shapes. Their size varies from units to tens of micrometers. Adsorption isotherms of formic, acetic, and propionic acids were constructed at a temperature of $295 \mathrm{~K}$. It is shown that they have an S-shaped character, therefore, adsorption is due to the formation of hydrogen bonds between the silanol groups of the hydrated POLYSORB and the carboxyl groups of acids. It is established that these isotherms are adequately described by the Freundlich model up to the saturation region. With an increase in the hydrocarbon radical, the adsorption capacity of acids decreases. The kinetics of acid adsorption on the polysorb surface was described using pseudo-first and pseudo-second order models. It was found that the adsorption kinetics of carboxylic acids is adequately described by the pseudo-first-order model. The time of onset of adsorption equilibrium is 30 seconds at a temperature of $295 \mathrm{~K}$.
\end{abstract}

\section{References}

[1] A.S. Shklyaeva, O.V. Vasilieva, and V.I. Kucuk. The study of physical and chemical properties aqueous dispersion of enterosorbent Polysorb MP. Butlerov Communications. 2013. Vol.35. No.8. P.94-99. ROIjbc-02/13-35-94

[2] A.A Chuyko, V.K. Pogorelyi. Medical chemistry of nanodispersed silica. Chemistry, physics and surface technology. 2006. Vol.11. No.12. P.346-357. (russian)

[3] E.S. Chambers, A. Viardot, A. Psichas et al. Effects of targeted delivery of propionate to the human colon on appetite regulation, body weight maintenance and adiposity in overweight adults. Gut. 2015. Vol.64. P.1744-1754. 